\title{
Fetal growth and impaired glucose tolerance in men and women
}

\author{
K. Phipps ${ }^{1}$, D.J.P. Barker ${ }^{1}$, C. N. Hales ${ }^{2}$, C.H.D.Fall ${ }^{1}$, C. Osmond ${ }^{1}$ and P. M.S. Clark ${ }^{2}$ \\ ${ }^{1}$ Medical Research Council Environmental Epidemiology Unit, University of Southampton, Southampton General Hospital, Southampton \\ and ${ }^{2}$ Department of Clinical Biochemistry, University of Cambridge, Addenbrooke's Hospital, Cambridge, UK
}

\begin{abstract}
Summary. A follow-up study was carried out to determine whether reduced fetal growth is associated with the development of impaired glucose tolerance in men and women aged 50 years. Standard oral glucose tolerance tests were carried out on 140 men and 126 women born in Preston (Lancashire, UK) between 1935 and 1943, whose size at birth had been measured in detail. Those subjects found to have impaired glucose tolerance or non-insulin-dependent diabetes mellitus had lower birthweight, a smaller head circumference and were thinner at birth. They also had a higher ratio of placental weight to birthweight. The prevalence of impaired glucose tolerance or diabetes fell from $27 \%$ in subjects who weighed $2.50 \mathrm{~kg}$ (5.5 pounds) or less at birth to $6 \%$ in those who weighed more than $3.41 \mathrm{~kg}$ ( 7.5 pounds) ( $p<0.002$ after adjusting for body mass index). Plasma glucose concentrations taken at 2-h in the glucose tolerance test fell progressively as
\end{abstract}

birthweight increased $(p<0.004)$, as did 2 -h plasma insulin concentrations $(p<0.001)$. The trends with birthweight were independent of duration of gestation and must therefore be related to reduced rates of fetal growth. These findings confirm the association between impaired glucose tolerance in adult life and low birthweight previously reported in Hertfordshire (UK), and demonstrate it in women as well as men. It is suggested that the association reflects the long-term effects of reduced growth of the endocrine pancreas and other tissues in utero. This may be a consequence of maternal undernutrition.

Key words: Impaired glucose tolerance, non-insulin-dependent diabetes mellitus, fetal growth, ponderal index at birth, placental weight to birthweight ratio.
A recent study of men 64 years of age showed that those who had lower birthweight and weight at one year of age had a higher prevalence of non-insulin-dependent diabetes mellitus in adult life [1]. Among these men, who lived in the county of Hertfordshire (UK), the percentage who had either non-insulin-dependent diabetes mellitus or impaired glucose tolerance fell progressively from $40 \%$ in those whose birthweight was $2.50 \mathrm{~kg}$ (5.5 pounds) or less to $14 \%$ in those whose birthweight was $4.31 \mathrm{~kg}$ ( 9.5 pounds) or more. These trends were independent of current body mass and socio-economic status. They are interpreted as the long-term effects of nutritional and other factors which reduce fetal and infant growth and impair the development of the endocrine pancreas and other tissues.

We describe here a study carried out to confirm the relationship between lower birthweight and impaired glucose tolerance in another population. The subjects were men and women aged 50 years. In the Hertfordshire study women were not included because tracing them is made more difficult by their change of name at marriage. In the
Hertfordshire birth records the only recorded measurement of the baby was birthweight. We therefore studied men and women born in a hospital where other birth measurements and the duration of gestation were recorded.

\section{Subjects and methods}

A standardised record form was kept for each woman admitted to the maternity ward at Sharoe Green Hospital, Preston (Lancashire, UK) between 1935 and 1943. The record included the date of the mother's last menstrual period and the baby's birthweight, placental weight, length from crown to heel, and head circumference. Weights were measured in pounds ( 1 pound $=0.45 \mathrm{~kg}$ ) and lengths and head circumferences in inches $(1$ inch $=2.54 \mathrm{~cm})$.

As described in a previous publication [2] we used the National Health Service central register to trace all babies born in the hospital between 1935 and 1943 . We traced 1122 (86\%), of whom 503 were still living in the county of Lancashire 449 of these took part in our first study of blood pressure. They agreed to be interviewed at home and were visited by one of three fieldworkers. The fieldworker had not seen the birth data recorded for the person. Height was measured with a portable stadiometer and weight with a portable 
Table 1. Differences in mean body size, currently and at birth, between men and women in Preston with and without impaired glucose tolerance or non-insulin-dependent diabetes mellitus

\begin{tabular}{|c|c|c|c|c|c|}
\hline & \multicolumn{5}{|c|}{ Difference (with-without) } \\
\hline & $\begin{array}{l}\text { Men } \\
\text { (14 with, } \\
126 \text { without) }\end{array}$ & $\begin{array}{l}\text { Women } \\
\text { (20with, } \\
106 \text { without) }\end{array}$ & $\begin{array}{l}\text { Total } \\
\text { (34 with, } \\
232 \text { without) }\end{array}$ & $\begin{array}{l}95 \% \\
\text { confidence } \\
\text { interval }\end{array}$ & $\begin{array}{l}\text { sex adjusted } \\
p \text {-value }\end{array}$ \\
\hline Height (m) & -0.07 & -0.04 & -0.05 & $(-0.07$ to -0.03$)$ & $<0.0001$ \\
\hline Weight (kg) & 8.9 & 2.2 & 5.1 & $(0.9$ to 9.2$)$ & 0.02 \\
\hline Body mass index $\left(\mathrm{kg} / \mathrm{m}^{2}\right)$ & 5.3 & 2.1 & 3.5 & $(2.1$ to 4.9$)$ & $<0.0001$ \\
\hline Birthweight $(\mathrm{kg})$ & -0.17 & -0.43 & -0.32 & $(-0.51$ to -0.13$)$ & 0.001 \\
\hline Length of gestation (days) ${ }^{\mathrm{a}}$ & -0.9 & -2.7 & -2.0 & $(-8.1$ to 4.2$)$ & 0.5 \\
\hline Placental weight $(\mathrm{kg})$ & 0.00 & -0.01 & 0.00 & $(-0.06$ to 0.05$)$ & 0.9 \\
\hline Placental to birthweight ratio & 0.013 & 0.027 & 0.021 & $(0.007$ to 0.036$)$ & 0.004 \\
\hline Head circumference at birth $(\mathrm{cm})$ & -0.7 & -1.0 & -0.9 & $(-1.5$ to -0.2$)$ & 0.009 \\
\hline
\end{tabular}

${ }^{a}$ Recorded for 220 subjects

Seca scale. The waist circumference and hip girth were measured. The father's occupation was used to define social class at birth, and current social class was derived from the subject's or husband's occupation.

After the interview the 393 subjects who lived in or close to Preston were asked to come to Sharoe Green Hospital in the morning following an overnight fast to have a blood sample taken. Six subjects previously diagnosed with diabetes were excluded. Of those asked 281 complied, and $266(69 \%)$ agreed to undergo a $75-\mathrm{g}$ oral glucose tolerance test. Measurements on the blood samples included plasma glucose and insulin concentrations at 0, 30 and $120 \mathrm{~min}$ and proinsulin and 32-33 split proinsulin concentrations at zero time. Plasma glucose was measured by a hexokinase method [3]. Plasma insulin, proinsulin and 32-33 split proinsulin concentrations were determined by two site immunometric assays with either ${ }^{125} \mathrm{I}$ or alkaline phosphatase as labels $[4,5]$. The insulin assay was standardised against the first International Reference Preparation coded 66/304 and the intact and split proinsulin assays against standards obtained from Lilly Research Laboratories (Indianapolis, Ind., USA).

\section{Statistical analysis}

The measurements of glucose, insulin, proinsulin and 32-33 split proinsulin have skewed distributions and we therefore transformed them in the analysis by using logarithms. Multiple linear and logistic regression were used to analyse the data.

\section{Results}

The age of the 266 men and women in Preston ranged from 46 to 54 years, with a mean of 50 years. Of these, 29 (11 men and 18 women) had impaired glucose tolerance, defined as a 2 -h plasma glucose concentration of 7.8 to $11.0 \mathrm{mmol} / \mathrm{l}$, and five (three men and two women) had newly-diagnosed non-insulin-dependent diabetes, defined as a 2-h plasma glucose concentration of $11.1 \mathrm{mmol} / \mathrm{l}$ or more. The subjects with non-insulin-dependent diabetes had a higher mean body mass index than those with impaired glucose tolerance, $36 \mathrm{~kg} / \mathrm{m}^{2}$ in the men and $31 \mathrm{~kg} / \mathrm{m}^{2}$ in the women compared with 30 and $27 \mathrm{~kg} / \mathrm{m}^{2}$, respectively. Compared with the other $232 \mathrm{men}$ and women, and adjusting for the unequal number of men and women, the 34 subjects with either impaired glucose tolerance or non-insulin-dependent diabetes were $5.0 \mathrm{~cm}$ shorter in stature, $5.1 \mathrm{~kg}$ heavier in weight and had a $3.5 \mathrm{~kg} / \mathrm{m}^{2}$ higher BMI, and a $4.1 \%$ higher waist to hip ratio (Table 1). Their mean birthweight was $0.3 \mathrm{~kg}$ less but

Table 2. Percentages of men and women with impaired glucose tolerance (IGT) or non-insulin-dependent diabetes mellitus according to birthweight

\begin{tabular}{|c|c|c|c|}
\hline $\begin{array}{l}\text { Birth- } \\
\text { weight } \\
(\mathrm{kg})\end{array}$ & $n$ & $\begin{array}{l}\% \text { with IGT } \\
\text { or newly- } \\
\text { diagnosed } \\
\text { non-insulin- } \\
\text { dependent } \\
\text { diabetes }\end{array}$ & $\begin{array}{l}\text { Odds ratio adjusted } \\
\text { for BMI ( } 95 \% \\
\text { confidence interval) }\end{array}$ \\
\hline \multicolumn{4}{|l|}{ Men } \\
\hline$\leq 2.50$ & 16 & 13 & $3.5(0.4$ to 28$)$ \\
\hline-2.95 & 31 & 13 & $1.8(0.3$ to 10$)$ \\
\hline-3.41 & 50 & 10 & $1.9(0.4$ to 9.9$)$ \\
\hline$>3.41$ & 43 & 7 & 1.0 \\
\hline Total & 140 & 10 & \\
\hline \multicolumn{4}{|l|}{ Women } \\
\hline$\leq 2.50$ & 14 & 43 & $12.1(2.0$ to 73$)$ \\
\hline-2.95 & 24 & 25 & $6.2(1.1$ to 35$)$ \\
\hline-3.41 & 49 & 12 & $2.3(0.4$ to 12$)$ \\
\hline$>3.41$ & 39 & 5 & 1.0 \\
\hline Total & 126 & 16 & \\
\hline \multicolumn{4}{|l|}{ All } \\
\hline$\leq 2.50$ & 30 & 27 & $6.4(1.8$ to 23$)$ \\
\hline-2.95 & 55 & 18 & $3.3(1.0$ to 11$)$ \\
\hline-3.41 & 99 & 11 & $1.9(0.6$ to 5.9$)$ \\
\hline$>3.41$ & 82 & 6 & 1.0 \\
\hline Total & 266 & 13 & $\begin{array}{l}\chi^{2} \text { for trend }=9.9 \\
p=0.002\end{array}$ \\
\hline
\end{tabular}


there was no difference in duration of gestation, which was estimated from the date of the mother's last menstrual period. There was no difference in mean placental weight but the placental weight to birthweight ratio was 0.021 higher. Mean head circumference was $0.9 \mathrm{~cm}$ smaller. A small difference was observed in mean length but the ponderal index (weight $/$ length ${ }^{3}$ ) was $1.6 \mathrm{~kg} / \mathrm{m}^{3}$ lower. All the differences, except for that in length, were statistically significant. Table 1 shows that the differences occurred both in men and women.

Table 2 shows that the prevalence of impaired glucose tolerance and non-insulin-dependent diabetes fell progressively from $27 \%$ in men and women whose birthweights were $2.50 \mathrm{~kg}$ (5.5 pounds) or less to $6 \%$ in those whose birthweights were more than $3.41 \mathrm{~kg}$ ( 7.5 pounds). Adjusting for BMI the odds ratios fell from 6.4 to 1.0. Men and women showed similar trends. The subjects were divided into four groups with approximately equal numbers of subjects, according to their ponderal index. The values of ponderal index were up to $21,23,25$, and more than $25 \mathrm{~kg} / \mathrm{m}^{3}$. The prevalence of impaired glucose tolerance and diabetes fell from $23 \%$ to $11 \%$ to $8 \%$ to $7 \%$, respectively.

Plasma glucose concentrations at 2-h fell with increasing birthweight ( $p=0.002$, after adjusting for BMI and sex). There was a similar trend in 2-h plasma insulin concentrations $(p=0.0002)$. Mean values were higher in women and results for men and women are shown separately in Table 3 . The trends were changed only slightly by adjustment for duration of gestation. Plasma glucose concentrations at 30-min also fell with increasing birthweight $(p=0.003)$. Plasma insulin concentrations at 30-min showed no trend. Fasting plasma glucose concentrations tended to fall with increasing birthweight though this trend was weak and not statistically significant. Fasting plasma insulin concentrations did not change with birthweight. Fasting plasma proinsulin concentrations fell with increasing birthweight ( $p=0.04$, Table 3 ). Fasting plasma

Table 3. Mean 2-h plasma glucose and insulin concentrations, fasting proinsulin concentrations, and body mass index, according to birthweight in men and women

\begin{tabular}{lllll}
\hline $\begin{array}{l}\text { Birth- } \\
\text { weight } \\
(\mathrm{kg})\end{array}$ & $\begin{array}{l}2 \text {-h } \\
\text { glucose } \\
(\mathrm{mmol} / \mathrm{l})\end{array}$ & $\begin{array}{l}\text { 2-h } \\
\text { insulin } \\
(\mathrm{pmol} / \mathrm{l})\end{array}$ & $\begin{array}{l}\text { Fasting } \\
\text { proinsulin } \\
(\mathrm{pmol} / \mathrm{l})\end{array}$ & $\begin{array}{l}\text { Body mass } \\
\text { index } \\
\left(\mathrm{kg} / \mathrm{m}^{2}\right)\end{array}$ \\
\hline Men & & & & \\
$\quad \leq 2.50$ & $5.7(16)$ & $172(16)$ & $3.7(14)$ & $25.3(16)$ \\
-2.95 & $5.5(31)$ & $169(30)$ & $3.8(31)$ & $27.6(31)$ \\
-3.41 & $5.6(50)$ & $142(49)$ & $3.5(48)$ & $26.4(50)$ \\
$>3.41$ & $5.3(43)$ & $129(42)$ & $3.4(41)$ & $27.2(43)$ \\
Total & $5.5(140)$ & $147(137)$ & $3.6(134)$ & $26.8(140)$ \\
SD & $1.3^{\mathrm{a}}$ & $2.2^{\mathrm{a}}$ & $1.9^{\mathrm{a}}$ & 4.1 \\
Women & & & & \\
$\quad \leq 2.50$ & $6.8(14)$ & $248(14)$ & $3.4(14)$ & $26.7(14)$ \\
-2.95 & $6.5(24)$ & $256(23)$ & $3.6(24)$ & $25.0(24)$ \\
-3.41 & $5.6(49)$ & $153(48)$ & $2.3(46)$ & $26.0(49)$ \\
$>3.41$ & $5.4(39)$ & $152(38)$ & $2.8(38)$ & $25.1(39)$ \\
Total & $5.8(126)$ & $178(123)$ & $2.8(122)$ & $25.6(126)$ \\
SD & $1.3^{\mathrm{a}}$ & $1.9^{\mathrm{a}}$ & $1.8^{\mathrm{a}}$ & 4.0 \\
\hline
\end{tabular}

${ }^{\text {a }}$ Geometric (based on log values).

Numbers of subjects in parentheses
Table 4. Mean 2-h plasma glucose and insulin concentrations according to the ratio of placental weight to birthweight in men and women

\begin{tabular}{|c|c|c|c|c|c|c|}
\hline \multirow{2}{*}{$\begin{array}{l}\text { Ratio of pla- } \\
\text { cental weight } \\
\text { to birthweight }\end{array}$} & \multicolumn{3}{|c|}{ 2-h glucose $(\mathrm{mmol} / \mathrm{l})$} & \multicolumn{3}{|c|}{ 2-h insulin $(\mathrm{pmol} / \mathrm{l})$} \\
\hline & Men & Women & Total & Men & Womer & Total \\
\hline-0.165 & 5.2 & 5.5 & 5.3 & 120 & 160 & 140 \\
\hline-0.186 & 5.6 & 5.6 & 5.6 & 139 & 178 & 158 \\
\hline-0.214 & 5.5 & 6.0 & 5.7 & 145 & 180 & 159 \\
\hline$>0.214$ & 5.7 & 6.4 & 6.0 & 183 & 201 & 190 \\
\hline Total & 5.5 & 5.8 & 5.6 & 147 & 178 & 161 \\
\hline
\end{tabular}

32-33 split proinsulin concentrations were not related to birthweight, but half of the values were below the level of detection by the assay.

In a previous analysis of the Preston subjects, of birth measurements in relation to later blood pressure, a high ratio of head circumference to length was used to define babies who were short at birth [6]. We used multiple regressions to analyse the independent effects of shortness and of thinness, defined by a low ponderal index, on 2-h plasma glucose and insulin concentrations, taking account of body mass. A high head circumference to length ratio was associated with both raised 2 -h plasma glucose $(p=0.09)$ and insulin concentrations $(p=0.01)$. A low ponderal index was independently associated with raised 2-h plasma glucose $(p=0.01)$ and insulin concentrations $(p=0.01)$.

In Table 4 the men and women have been divided by quartiles of the ratio of placental weight to birthweight. Plasma glucose and 2-h insulin concentrations rose from the lowest to the highest fourths $(p=0.01$ and 0.006 respectively). The trends in both sexes were similar. There were no corresponding changes in 30-min or fasting plasma glucose and insulin concentrations, nor with proinsulin concentrations.

The prevalence of impaired glucose tolerance and diabetes, and the concentrations of plasma glucose, insulin and proinsulin were similar in each social class, defined currently or at birth. The associations with birthweight were seen in each social class group.

\section{Discussion}

These findings confirm and extend the observations made in our previous study of an older group of men living in Hertfordshire. They confirm that impaired glucose tolerance and non-insulin-dependent diabetes in adult life are associated with lower birthweight in people living in another part of the country and in women as well as men. This strengthens the conclusion that the association is not due to unknown confounding variables. This conclusion is further strengthened by the recent finding that 30 -min plasma glucose concentrations were inversely related to birthweight in 21-year-old men [7].

As in the Hertfordshire study 2-h plasma glucose and insulin concentrations fell as birthweight increased and 30-min plasma glucose concentrations showed a similar trend. Glucose and insulin concentrations fell progres- 
sively up to the highest birthweights. In Preston only three babies reached weights of more than $4.31 \mathrm{~kg}$ ( 9.5 pounds). In Hertfordshire, however, there were 28 babies of this weight, and they had the lowest 2 -h plasma glucose concentrations. Since mothers with diabetes in pregnancy tend to have large babies one might expect some large babies to show evidence of impaired glucose metabolism. This effect may not be apparent because the numbers of such babies are small in relation to the number of babies who are heavy because of good fetal nutrition. In both Preston and Hertfordshire there was a fall in plasma proinsulin concentrations with birthweight, though this was not statistically significant in Hertfordshire. We do not know whether this association reflects insulin deficiency, as a consequence of poor fetal growth, or insulin resistance.

In Hertfordshire the only measurement recorded at birth was birthweight. The birth records in Preston were more detailed and included duration of gestation, head circumference, length and placental weight. The trends with birthweight in prevalence of impaired glucose tolerance or diabetes and in 2-h plasma glucose and insulin concentrations were independent of duration of gestation. They must therefore be related to reduced rates of fetal growth. Our findings show that raised 2 -h plasma glucose and insulin concentrations are found in two groups of babies, with different patterns of impaired fetal growth. One group is thin at birth, as shown by a low ponderal index. A recent study showed that such babies have a raised fetal heart rate at 18 weeks [8], which suggests that their reduced fetal growth begins in early gestation. The other group of babies are short in relation to their head size, an asymmetrical pattern of development thought to reflect reduced growth in late gestation. We are currently studying these two groups in more detail to determine if their glucose and insulin metabolism differs.

Men and women with impaired glucose tolerance and non-insulin-dependent diabetes had a high ratio of placental weight to birthweight. Plasma glucose and insulin concentrations taken at 2 -h rose as this ratio increased. Disproportionately large placental size may be a consequence of maternal under-nutrition. It occurs in babies whose mothers were anaemic during pregnancy $[9$, 10] and can be produced in sheep by depriving the ewe of food in early pregnancy $[11,12]$. Impaired glucose tolerance and non-insulin-dependent diabetes may therefore be a consequence of maternal under-nutrition.

Acknowledgements. We are grateful to all the men and women who gave us their time; to the medical records department at Sharoe Green Hospital, Preston, who preserved the records and allowed us to use them; and to the staff of the NHS Central Register, Southport and of Lancashire Family Health Services Authority who helped us to locate the subjects. The fieldwork was carried out by J Hart,
M Livesey and J Peace. H Whiteside, C Carr, L Cox, A Haines, $D$ Wong, and staff of the NHS section of the Department of Clinical Biochemistry, Addenbrooke's hospital gave technical assistance. Laboratory staff at the Royal Preston Hospital stored the blood samples. The study was funded by the Medical Research Council, the British Diabetic Association and Lilly Research Laboratories.

\section{References}

1. Hales CN, Barker DJP, Clark PMS et al. (1991) Fetal and infant growth and impaired glucose tolerance at age 64 years. Br Med J 303: 1019-1022

2. Barker DJP, Bull AR, Osmond C, Simmonds SJ (1990) Fetal and placental size and risk of hypertension in adult life. Br Med J 301: 259-262

3. Kunst A, Draeger B, Ziegenhorn J (1983) UV-methods with hexokinase and glucose-6-phosphate dehydrogenase. In: Bergmeyer HU (ed) Methods of enzymatic analysis, Vol VI. Weinheim: Verlag Chemie, Deerfield, pp 163-172

4. Sobey WJ, Beer SF, Carrington CA et al. (1989) Sensitive and specific two-site immuno-radiometric assays for human insulin, proinsulin, 65-66 split and 32-33 split proinsulins. Biochem J 260:535-541

5. Alpha B, Cox L, Crowther N, Clark PMS, Hales CN (1992) Sensitive amplified immunoenzymometric assays (IEMA) for human insulin and intact proinsulin. Eur J Clin Chem Clin Biochem 30: 27-32

6. Barker DJP, Godfrey KM, Osmond C, Bull A (1992) The relation of fetal length, ponderal index and head circumference to blood pressure and the risk of hypertension in adult life. Paediatr Perinat Epidemiol 6: 34-44

7. Robinson S, Walton RJ, Clark PM, Barker DJP, Hales CN, Osmond C (1992) The relation of fetal growth to plasma glucose in young men. Diabetologia 35: 444-446

8. Robinson SM, Wheeler T, Hayes MC, Barker DJP, Osmond C (1991) Fetal heart rate and intrauterine growth. Br J Obstet Gynaecol 98: 1223-1227

9. Beischer MA, Sivasamboo R, Vohra S, Silpisorn Rosal S, Reid S (1970) Placental hypertrophy in severe pregnancy anaemia. J Obstet Gynaecol (Br Commw) 77: 398-409

10. Godfrey KM, Redman CWG, Barker DJP, Osmond C (1991) The effect of maternal anaemia and iron deficiency on the ratio of fetal weight to placental weight. Br J Obstet Gynaecol 98: 886891

11. Farchney GJ, White GA (1987) Effects of maternal nutritional status on fetal and placental growth and on fetal urea synthesis. Austr J Biol Sci 40: 365-377

12. McCrabb GJ, Egan AR, Hosking BJ (1991) Maternal undernutrition during mid-pregnancy in sheep. Placental size and its relationship to calcium transfer during late pregnancy. Br J Nutr 65: 157-168

Received: 13 August 1992

and in revised form: 12 October 1992

Prof. D.J.P.Barker

Medical Research Council Environmental Epidemiology Unit

Southampton General Hospital

Southampton S09 4XY

UK 